\title{
The use of web-based interventions to prevent excessive weight gain
}

\author{
Siti Maon*, Sisira Edirippulige*, Robert Ware ${ }^{\dagger *}$ and Jennifer Batch ${ }^{\S * *}$ \\ *Centre for Online Health, University of Queensland, Brisbane, Australia; †'School of Population Health, University of Queensland, Brisbane, \\ Australia; ${ }^{\ddagger}$ Queensland Children's Medical Research Institute, University of Queensland, Brisbane, Australia; ${ }^{\S}$ School of Medicine, University \\ of Queensland, Brisbane, Australia; **Department of Endocrinology and Diabetes, Royal Children's Hospital, Brisbane, Australia
}

\begin{abstract}
Summary
We reviewed web-based interventions for overweight and obesity prevention. A literature search was conducted using seven electronic databases. Manually searched articles were also included. Thirty studies fulfilled the inclusion criteria. Of these, 13 studied physical activity, eight studied dietary practices and nine studied a combination of physical activity and dietary practice. Twenty-eight of the studies (93\%) reported positive changes in moderate to vigorous physical activity level, fruit and vegetable intake and psychological factors. A meta-analysis showed there were improvements, though not significant, in fruit and vegetable consumption (standardised mean difference, $\mathrm{SMD}=0.61 ; 95 \% \mathrm{Cl}=-0.13$ to 1.35 ) and physical activity $(\mathrm{SMD}=0.15 ; 95 \% \mathrm{Cl}=-0.06$ to 0.35$)$. The review suggests that web-based interventions are a useful educational tool for increasing awareness and making healthy behaviour changes in relation to an excessive weight gain problem.
\end{abstract}

\section{Introduction}

The rapid increase in people who are overweight or obese is a major public health concern throughout the world. The World Health Organization has recognised obesity as a global health epidemic. ${ }^{1}$ It is predicted that there will be 700 million obese people and 2.3 billion who are overweight by $2015 .{ }^{1}$ Overweight and obesity are related to excessive weight gain resulting from a long-term energy imbalance, where energy consumption exceeds expenditure. Once obesity has developed, it is difficult to manage the weight. Thus, early detection and prevention are considered to be key strategies in addressing the problem. ${ }^{2}$ Poor diet and low physical activity are the most common contributing factors to overweight and obesity. A large number of studies have found that a healthy diet with a high intake of fruit and vegetables can reduce the long-term risk of obesity. ${ }^{3-5}$ In addition, physical activity is helpful. ${ }^{6-8}$ These studies have concluded that interventions which improve diet and exercise habits lead to encouraging outcomes. Therefore, there is a need for effective measures to motivate people to adopt healthier eating patterns and increase their level of exercise.

A number of review studies have examined the effectiveness of web technologies in health promotion,

Accepted 25 August 2011

Correspondence: Siti Maon, Centre for Online Health, University of Queensland, Level 3, Foundation Building, Royal Children's Hospital, Herston,

Queensland 4029, Australia (Fax: +61 73346 4705; Email: s.maon@uq.edu.au) health education and health behaviour change, ${ }^{9-11}$ management and treatment. ${ }^{10,12}$ The aim of the present review was to assess the evidence related to web-based interventions for overweight and obesity prevention.

\section{Methods}

The Pubmed, Medline (Ovid), PsycINFO, Embase, CINAHL, Scopus and Web of Knowledge databases (up to 15 March 2010) were searched to identify all studies that considered the effect of web-based interventions on diet and physical activity. The search terms used were: Internet, online, education, web technologies, physical activity, eating, weight management, prevention, overweight and obesity. We searched for terms singly and in combination. Studies were restricted to peer reviewed English-language publications. Reference lists from retrieved relevant articles were examined to identify additional literature. The years searched were from 2000. The literature searches were performed between May and August, 2010. One review author screened titles and abstracts obtained from the database searches. Two review authors independently reviewed potentially relevant articles. Disagreements were resolved by consensus.

\section{Selection criteria}

Studies were included if they targeted healthy participants and examined the effect of web-based interventions on 
eating patterns, physical activity levels or a combination of both. In this review, the effect of web-based techniques includes modification of physical activity and eating patterns. Changes in knowledge, attitudes and awareness are also included. To be included, study outcomes had to be measured both pre- and post intervention. Studies where web-based techniques were used as either the main intervention or an additional component were included. Studies were excluded if the target participants were receiving medications or underwent treatment during the intervention. Studies focusing on weight loss and disease management were excluded.

\section{Analysis}

Results of meta-analyses were expressed using the standardised mean difference (SMD). Data were pooled into the outcomes portions of fruit and vegetables consumed, and minutes of moderate/vigorous physical activity undertaken. We used random-effects models. The data were analysed using a standard package (Stata version 11.1, StataCorp, College Station, TX, USA).

\section{Results}

In total, 1264 studies were screened based on titles and abstracts. A total of 30 studies met the inclusion criteria and were included in the review. The characteristics of the studies are summarised in Table 1. Overall, 12,500 healthy participants were engaged in the 30 studies. Among them, only $1740(14 \%)$ participants were children and adolescents. However, there were large differences in the sample sizes. Six of the 30 studies had recruited more than 500 participants at baseline, ${ }^{13-18}$ while six had sample sizes of less than $100 .{ }^{19-24}$

More than half (18 studies) of the studies were carried out in the US, four (13\%) in the Netherlands, three $(10 \%)$ in Australia, two (7\%) each in Belgium and the UK, and one (3\%) in Germany. Twenty studies (67\%) were conducted on adult populations, with participants recruited through workplaces, academic institutions and in a community setting. Of the eight studies involving children and adolescents, four (50\%) were conducted in schools.

From the 30 studies, 13 (43\%) were focused on physical activity, ${ }^{14,15,17,20,21,25-32}$ eight (27\%) on healthy

Table 1 General characteristics of the reviewed studies

\begin{tabular}{|c|c|c|c|}
\hline Outcomes & Studies & Participants & Design \\
\hline \multirow[t]{8}{*}{ Eating practices } & Alexander et al. $(2010)^{13}$ & 2540 adults & $\begin{array}{l}\text { Focus: Fruit and Vegetables Design: Randomised Controlled Trial (RCT) Recruitment: } \\
\text { Organizational Network (Cancer Research Network) Location: USA }\end{array}$ \\
\hline & Long et al. $(2004)^{34}$ & 121 adolescents & Focus: Healthy Eating Design: Quasi-experimental design Recruitment: School Location: USA \\
\hline & $\begin{array}{l}\text { Mangunkusomo et al. } \\
(2007)^{35}\end{array}$ & 486 children & $\begin{array}{l}\text { Focus: Healthy Eating Design: Cluster-randomised experimental design Recruitment: School } \\
\text { Location: The Netherlands }\end{array}$ \\
\hline & Oenema et al. $(2001)^{36}$ & 198 adults & Focus: Nutrition Design: RCT Recruitment: Workplace Location: The Netherlands \\
\hline & Oenema et al. $(2005)^{22}$ & 61 adults & Focus: Nutrition Design: RCT Recruitment: Workplace Location: The Netherlands \\
\hline & Papadaki et al. (2005) $)^{23}$ & 72 female & Focus: Healthy Eating Design: Quasi-experimental design Recruitment: Workplace Location: UK \\
\hline & Park et al. $(2008)^{37}$ & 111 adults & Focus: Nutrition Design: RCT Recruitment: Media Location: USA \\
\hline & Buller et al. $(2008)^{33}$ & 762 adults & Focus: Nutrition Design: RCT Recruitment: Community Location: USA \\
\hline \multirow[t]{13}{*}{ Physical activity } & Dunton et al. $(2008)^{25}$ & 156 women & Focus: PA Design: RCT Recruitment: Community Location: USA \\
\hline & Ferney et al. (2009) 26 & 106 adults & Focus :PA Design: RCT Recruitment: Neighbourhood Location: Australia \\
\hline & Hurling et al. (2007) 20 & 77 adults & Focus: PA Design: RCT Recruitment: Community Location: UK \\
\hline & Jago et al. $(2006)^{27}$ & 473 children & Focus: PA Design: RCT Recruitment: Boy Scouts Location: USA \\
\hline & Marcus et al. $(2007)^{28}$ & 249 adults & Focus: PA Design: RCT Recruitment: Newspaper adverts Location: USA \\
\hline & Marks et al. $(2006)^{29}$ & 319 adolescent girls & Focus: PA Design: RCT Recruitment: School setting Location: USA \\
\hline & Marshall et al. (2003) ${ }^{14}$ & 655 adults & Focus: PA Design: RCT Recruitment: Workplace Location: Australia \\
\hline & $\begin{array}{l}\text { Napolitano et al. } \\
\quad(2003)^{21}\end{array}$ & 65 women & Focus: PA Design: RCT Recruitment: Workplace Location: USA \\
\hline & $\begin{array}{l}\text { Slootmaker et al. } \\
(2009)^{30}\end{array}$ & 102 workers & Focus: PA Design: RCT Recruitment: Workplace Location: The Netherlands \\
\hline & Spittaels et al. $(2007)^{31}$ & 434 adults & Focus: PA Design: RCT Recruitment: Workplace Location: Belgium \\
\hline & Steele et al. $(2009)^{32}$ & 192 adults & Focus: PA Design: RCT Recruitment: Workplace Location: Australia \\
\hline & Spittaels et al. (2007) ${ }^{15}$ & 526 adults & Focus: PA Design: RCT Recruitment: Workplace Location: Belgium \\
\hline & Wanner et al. (2009) ${ }^{17}$ & 1531 adults & Focus: PA Design: RCT Recruitment: Media adverts Location: Germany \\
\hline \multirow[t]{9}{*}{$\begin{array}{l}\text { Physical activity } \\
\text { and eating }\end{array}$} & $\begin{array}{l}\text { Baranowski et al. } \\
(2003)^{19}\end{array}$ & $\begin{array}{l}35 \text { African- } \\
\text { American girls }\end{array}$ & Focus: PA and Nutrition Design: RCT Recruitment: School Location: USA \\
\hline & Cook et al. $(2007)^{38}$ & 419 adults & Focus: Diet, Stress and PA Design: RCT Recruitment: Workplace Location: USA \\
\hline & Franko et al. $(2008)^{39}$ & $\begin{array}{l}476 \text { college } \\
\text { students }\end{array}$ & Focus: Nutrition and PA Design: RCT Recruitment: Higher institutions Location: USA \\
\hline & Frenn et al. $(2003)^{40}$ & 130 adolescents & Focus: Nutrition and PA Design: Quasi experimental Recruitment: School Location: USA \\
\hline & Frenn et al. $(2005)^{41}$ & 103 school children & Focus: Nutrition and PA Design: Quasi experimental Recruitment: School Location: USA \\
\hline & Gow et al. $(2010)^{42}$ & $\begin{array}{l}170 \text { college } \\
\text { students }\end{array}$ & Focus: Healthy eating and PA Design: RCT Recruitment: Public university Location: USA \\
\hline & Sternfeld et al. (2009) ${ }^{16}$ & 787 employees & Focus: Healthy eating and PA Design: RCT Recruitment: Workplace Location: USA \\
\hline & Thompson et al. $(2008)^{24}$ & $\begin{array}{l}73 \text { African American } \\
\text { girls }\end{array}$ & Focus: Healthy eating and PA Design: RCT Recruitment: Media Location: USA \\
\hline & Winett et al. $(2007)^{18}$ & 1071 adults & Focus: Healthy eating and PA Design: RCT Recruitment: Churches Location: USA \\
\hline
\end{tabular}


eating ${ }^{13,22,23,33-37}$ and nine (30\%) focused on the combination of both. ${ }^{16,18,19,24,38-42}$ Most interventions targeted changes in knowledge, awareness, attitudes, motivation, self-efficacy and behaviour. Most studies (87\%) were randomized controlled trials (RCTs) although four studies were non-randomized controlled trials. Interventions were delivered using both synchronous and asynchronous techniques, such as websites (28 studies), Internet video ( 2 studies), discussion boards (6 studies), chat sessions (2 studies), online coaching (2 studies) and email (14 studies). Ten studies employed tailored web-based programmes to deliver information, advice and feedback messages. The majority of studies (23 of 30) compared web-based interventions to other interventions, whereas seven studies compared interventions to usual care. Seven studies used different delivery modes (such as printed material or face-to-face) in the control or comparison condition. Sixteen studies used a standard or low-intensity web-based intervention as the comparison. Participants in the control group of two studies received usual assignments for their class activities compared to intervention group. ${ }^{40,41}$ Furthermore, several studies utilized email reminders about website visits $(n=8)$ or other interventions $(n=9)$. Five studies used physical encounters such as one-to-one sessions, counselling sessions, troop and class meetings as adjuncts to web interventions. Only two studies employed professional assistance like a counsellor or a nurse. Of the 30 included studies, 15 provided psycho-education and modules to participants, 10 presented tailored feedback and messages, and three used other techniques such as comic characters and video format. The types of treatments given to the control groups are shown in Figure 1. In addition, incentives (9 studies) and email reminders (14 studies) were employed in order to increase participation and retention in the studies, especially to boost the web usage.

\section{Outcomes of web-based interventions}

In general, the studies showed positive effects. The majority of studies (93\%) demonstrated the effectiveness of web-based interventions to motivate participants to engage in healthy eating and active living. Only four (14\%) studies showed significant effects on increase of knowledge, intention to change, awareness and self-efficacy in relation to healthy eating practices. Of the eight studies investigating healthy eating habits, four (14\%) reported

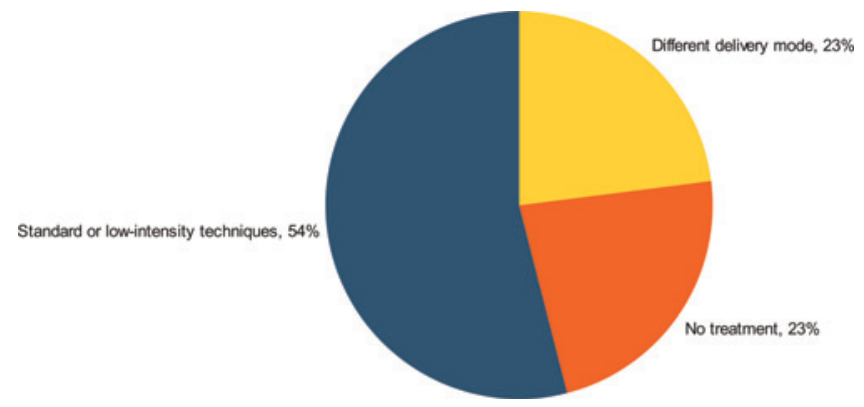

Figure 1 Types of treatments for control groups $(n=30)$ positive changes such as increased fruit or vegetable consumption. ${ }^{13,20,23,33}$ Seven of 13 studies showed significant effects on physical activity levels, such as increased walking or decreased sedentary behaviour. Seven (25\%) studies showed significant results on targeted behaviour, i.e. in healthy eating and exercise. However, nine (32\%) studies did not show significant differences between intervention and control groups. The web-based interventions and their effects are summarised in Table 2 (see http://jtt.rsmjournals.com/lookup/suppl/doi:10.1258/ jtt.2011.110306/-/DC1).

A meta-analysis was conducted using information from the three studies with extractable data for the outcome of portions of fruit and vegetables consumed daily. ${ }^{19,24,39}$ The chi-square test of heterogeneity $(P<0.001)$ indicated that a meta analysis was not appropriate. In two studies, a significant increase in the number of servings of fruit and vegetables consumed was observed $(\mathrm{MD}=0.8$ [95\%CI, 0.7 to 0.9$])^{19}$ and $\mathrm{MD}=0.5(95 \% \mathrm{CI}, 0.2 \text { to } 0.8)^{39}$ and in the remaining study there was little difference between intervention groups $(\mathrm{MD}=0.1[95 \% \mathrm{CI},-1.1$ to 1.3$]){ }^{24}$ There were four studies with extractable data for the outcome of moderate to vigorous weekly physical activity. ${ }^{15,25,26,31}$ Individuals who received the web-based intervention undertook greater physical activity, although the difference was not significant: $\mathrm{SMD}=0.15(95 \% \mathrm{CI}$, -0.06 to $0.35, P=0.16)$; test of heterogeneity, $P=0.16$ and $\mathrm{I}^{2}=41 \%$, see Figure 2 .

Positive outcomes were also associated with interactive interventions. Half of the studies employed interactive tools such as email, discussion boards, chat sessions, activity planning, personalised advice and feedback messages. Ten studies employed tailoring mechanisms in giving advice and feedback to participants. All these studies showed positive outcomes.

The majority of studies with web-based programmes and theory-based interventions also showed positive outcomes. However, it is important to examine the effect in relation to the duration of the interventions. Three (10\%) studies showed positive effects when outcomes were measured immediately after the end of the interventions. ${ }^{36,37,40}$ Eleven (37\%) studies that lasted three months or less demonstrated positive outcomes. Thirteen (43\%) studies with an interventions of 3-6 months showed positive results. Only three (10\%) interventions that lasted longer than six months were reported to have positive results. ${ }^{13,26,28}$

\section{Discussions}

The majority of studies (28 of 30; 93\%) involving web-based interventions resulted in positive changes in knowledge, attitude, awareness and behaviour of the participants. This suggests that web-based technologies are capable of promoting healthy lifestyles and managing healthy weight. 


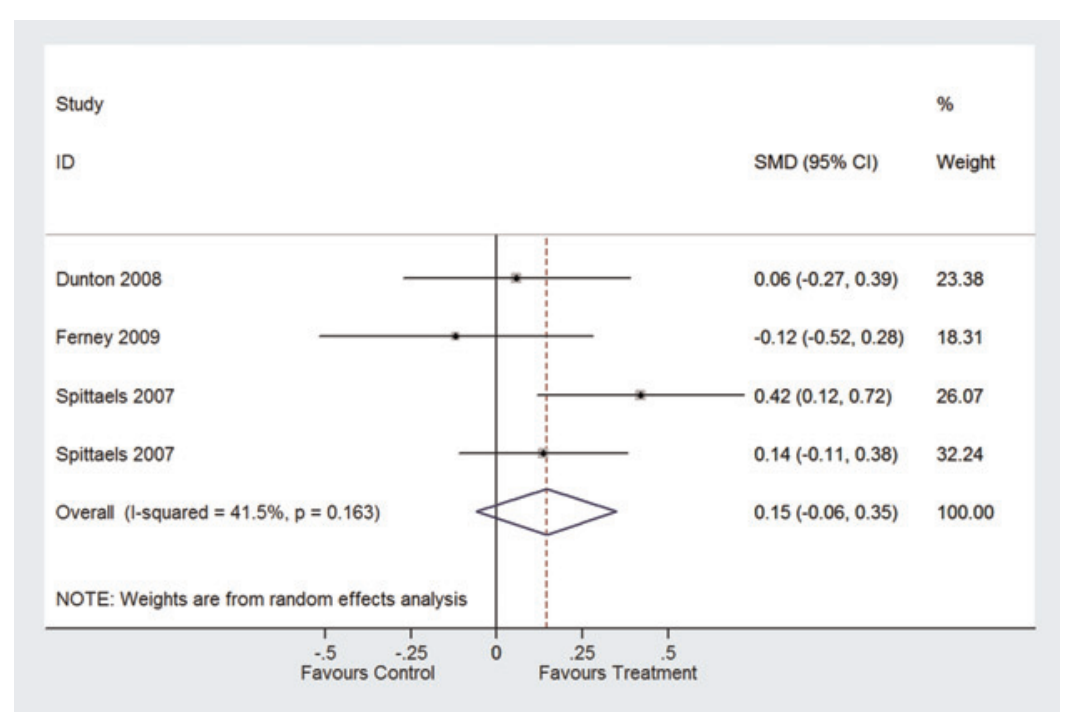

Figure 2 Portions of fruit and vegetables consumed daily

Studies have shown that improved diet and exercise patterns have positive effects in controlling excessive weight gain. ${ }^{2}$ The studies that used tailored web interventions increased the interactivity between the users. Interactive web interventions offered personalized advice, education and feedback messages about health behaviour. They also served as attractive features for people to continue using the websites. This is aligned with the findings of a systematic review of the literature on physical activity and dietary behaviour that observed individualisation as an important reason why the computer-tailored intervention had become effective in nutrition education. ${ }^{12}$ However, studies with a tailored web-based physical activity programme were not effective in increasing the level of physical activity among users. Hurling and colleagues therefore concluded that the design of a web-based intervention is crucial to ensure that key messages are clearly communicated to the users. It is important to consider the views and preferences of users in the development of web programs, particularly for children and adolescents. ${ }^{43}$

Most of the studies reviewed showed positive effects, particularly the ones that had a short duration of intervention. The effects of the interventions declined as the length of time from the end of the intervention increased, suggesting that the effects of web-based interventions are short-lived. This is probably due to the problem of engaging and retaining people to use websites. Studies have shown that email communication is a useful tool to increase the rate of repeated participation in websites. ${ }^{44}$ For example, one study involving adults reported that participants who accessed and responded to email messages tended to consume more fruit and vegetables compared to those who did not. ${ }^{44}$ Leslie and colleagues concluded that the lack of engagement in the interventions may be an important factor for behaviour change. ${ }^{45}$

More studies are required to investigate strategies to engage and retain people in using websites. For example, mobile technologies and web 2.0 technologies (social networking) may be important. The present review also found that few studies have investigated the effectiveness of web-based technologies for the benefit of children and adolescents.

In summary, the review showed that the use of web interventions has positive results in educating and raising awareness of healthy eating and exercise practices. Evidence suggests that web interventions can positively affect behaviour changes. Therefore, it is fair to say that web interventions can be effectively used to support those who suffer from weight gain problems. Web techniques as a community health tool can be effectively used in one of the serious global problems facing the humanity - obesity. However, web design, and the engagement and retention of users in web-based activities, are areas that need further investigation.

Acknowledgements: We are grateful for financial support for a PhD project provided by the Ministry of Higher Education and Universiti Teknologi MARA, Malaysia.

\section{References}

1 World Health Organization. Obesity and Overweight, Fact Sheet No 311. Geneva: WHO, 2006

2 Collins CE, Warren J, Neve M, McCoy P, Stokes BJ. Measuring effectiveness of dietetic interventions in child obesity: a systematic review of randomized trials. Arch Pediatr Adolesc Med 2006;160:906-22

3 Epstein LH, Gordy CC, Raynor HA, Beddome M, Kilanowski CK, Paluch R. Increasing fruit and vegetable intake and decreasing fat and sugar intake in families at risk for childhood obesity. Obes Res 2001;9:171-8

4 Epstein LH, Paluch RA, Beecher MD, Roemmich JN. Increasing healthy eating vs. treducing high energy-dense foods to treat pediatric obesity. Obesity (Silver Spring) 2008;16:318-26

5 He K, Hu FB, Colditz GA, Manson JE, Willett WC, Liu S. Changes in intake of fruits and vegetables in relation to risk of obesity and weight gain among middle-aged women. Int J Obes Relat Metab Disord 2004;28:1569-74

6 Cleland VJ, Dwyer T, Venn AJ. Physical activity and healthy weight maintenance from childhood to adulthood. Obesity (Silver Spring) 2008;16:1427-33 
7 Pate RR, Ward DS, Saunders RP, Felton G, Dishman RK, Dowda M. Promotion of physical activity among high-school girls: a randomized controlled trial. Am J Public Health 2005;95:1582-7

8 Steinbeck KS. The importance of physical activity in the prevention of overweight and obesity in childhood: a review and an opinion. Obes Rev 2001;2:117-30

9 van den Berg MH, Schoones JW, Vliet Vlieland TP. Internet-based physical activity interventions: a systematic review of the literature. J Med Internet Res 2007;9:e26

10 Norman GJ, Zabinski MF, Adams MA, Rosenberg DE, Yaroch AL, Atienza AA. A review of e-health interventions for physical activity and dietary behavior change. Am J Prev Med 2007;33:336-45

11 Wantland DJ, Portillo CJ, Holzemer WL, Slaughter R, McGhee EM. The effectiveness of web-based vs. non-web-based interventions: a meta-analysis of behavioral change outcomes. J Med Internet Res 2004;6:e40

12 Kroeze W, Werkman A, Brug J. A systematic review of randomized trials on the effectiveness of computer-tailored education on physical activity and dietary behaviors. Ann Behav Med 2006;31:205-23

13 Alexander GL, McClure JB, Calvi JH, et al. A randomized clinical trial evaluating online interventions to improve fruit and vegetable consumption. Am J Public Health 2010;100:319-26

14 Marshall AL, Leslie ER, Bauman AE, Marcus BH, Owen N. Print versus website physical activity programs: a randomized trial. Am J Prev Med 2003;25:88-94

15 Spittaels H, De Bourdeaudhuij I, Brug J, Vandelanotte C. Effectiveness of an online computer-tailored physical activity intervention in a real-life setting. Health Educ Res 2007;22:385-96

16 Sternfeld B, Block C, Quesenberry CP, et al. Improving diet and physical activity with ALIVE: a worksite randomized trial. Am J Prev Med 2009;36:475-83

17 Wanner M, Martin-Diener E, Braun-Fahrländer C, Bauer G, Martin BW. Effectiveness of active-online, an individually tailored physical activity intervention, in a real-life setting: randomized controlled trial. J Med Internet Res 2009;11:e23

18 Winett RA, Anderson ES, Wojcik JR, Winett SG, Bowden T. Guide to health: nutrition and physical activity outcomes of a group-randomized trial of an Internet-based intervention in churches. Ann Behav Med 2007;33:251-61

19 Baranowski T, Baranowski JC, Cullen KW, et al. The Fun, Food, and Fitness Project (FFFP): the Baylor GEMS pilot study. Ethn Dis 2003;13 (Suppl. 1):S30-9

20 Hurling R, Catt M, Boni MD, et al. Using internet and mobile phone technology to deliver an automated physical activity program: randomized controlled trial. J Med Internet Res 2007;9:e7

21 Napolitano MA, Fotheringham M, Tate D, et al. Evaluation of an internet-based physical activity intervention: a preliminary investigation. Ann Behav Med 2003;25:92-9

22 Oenema A, Tan F, Brug J. Short-term efficacy of a web-based computer-tailored nutrition intervention: main effects and mediators. Ann Behav Med 2005;29:54-63

23 Papadaki A, Scott JA. The Mediterranean eating in Scotland experience project: evaluation of an Internet-based intervention promoting the Mediterranean diet. Br J Nutr 2005;94:290-8

24 Thompson D, Baranowski T, Cullen K, et al. Food, fun, and fitness internet program for girls: pilot evaluation of an e-Health youth obesity prevention program examining predictors of obesity. Prev Med 2008;47:494-7

25 Dunton GF, Robertson TP. A tailored Internet-plus-email intervention for increasing physical activity among ethnically-diverse women. Prev Med 2008;47:605-11
26 Ferney SL, Marshall AL, Eakin EG, Owen N. Randomized trial of a neighborhood environment-focused physical activity website intervention. Prev Med 2009;48:144-50

27 Jago R, Baranowski T, Baranowski JC, et al. Fit for Life Boy Scout badge: outcome evaluation of a troop and Internet intervention. Prev Med 2006;42:181-7

28 Marcus BH, Lewis BA, Williams DM, et al. comparison of Internet and print-based physical activity interventions. Arch Intern Med 2007; 167:944-9

29 Marks JT, Campbell MK, Ward DS, Ribisl KM, Wildemuth BM, Symons MJ. A comparison of web and print media for physical activity promotion among adolescent girls. J Adolesc Health 2006;39:96-104

30 Slootmaker SM, Chinapaw MJ, Schuit AJ, Seidell JC, Van Mechelen W. Feasibility and effectiveness of online physical activity advice based on a personal activity monitor: randomized controlled trial. J Med Internet Res 2009;11:e27

31 Spittaels H, De Bourdeaudhuij I, Vandelanotte C. Evaluation of a website-delivered computer-tailored intervention for increasing physical activity in the general population. Prev Med 2007;44:209-17

32 Steele RM, Mummery WK, Dwyer T. A comparison of face-to-face or internet-delivered physical activity intervention on targeted determinants. Health Educ Behav 2009;36:1051-64

33 Buller DB, Woodall WG, Zimmerman DE, et al. Randomized trial on the 5 a day, the Rio Grande Way Website, a web-based program to improve fruit and vegetable consumption in rural communities. J Health Commun 2008; 13:230-49

34 Long JD, Stevens KR. Using technology to promote self-efficacy for healthy eating in adolescents. J Nurs Scholarsh 2004;36:134-9

35 Mangunkusumo RT, Brug J, de Koning HJ, van der Lei J, Raat H. School-based internet-tailored fruit and vegetable education combined with brief counselling increases children's awareness of intake levels. Public Health Nutr 2007;10:273-9

36 Oenema A, Brug J, Lechner L. Web-based tailored nutrition education: results of a randomized controlled trial. Health Educ Res 2001;16:647-60

37 Park A, Nitzke S, Kritsch K, et al. Internet-based interventions have potential to affect short-term mediators and indicators of dietary behavior of young adults. J Nutr Educ Behav 2008;40:288-97

38 Cook RF, Billings DW, Hersch RK, Back AS, Hendrickson A. A field test of a web-based workplace health promotion program to improve dietary practices, reduce stress, and increase physical activity: randomized controlled trial. J Med Internet Res 2007;9:e17

39 Franko DL, Cousineau TM, Trant M, et al. Motivation, self-efficacy, physical activity and nutrition in college students: randomized controlled trial of an internet-based education program. Prev Med 2008;47:369-77

40 Frenn M, Malin S, Bansal N, et al. Addressing health disparities in middle school students' nutrition and exercise. J Community Health Nurs 2003;20:1-14

41 Frenn M, Malin S, Brown RL, et al. Changing the tide: an Internet/video exercise and low-fat diet intervention with middle-school students. Appl Nurs Res 2005;18:13-21

42 Gow RW, Trace SE, Mazzeo SE. Preventing weight gain in first year college students: an online intervention to prevent the "freshman fifteen". Eat Behav 2010;11:33-9

43 Hurling R, Fairley BW, Dias MB. Internet-based exercise intervention systems: are more interactive designs better? Psychol Health 2006;21:757-72

44 McNeill LH, Viswanath K, Bennett GG, Puleo E, Emmons KM. Feasibility of using a web-based nutrition intervention among residents of multiethnic working-class neighborhoods. Prev Chronic Dis 2007;4:A55

45 Leslie E, Marshall AL, Owen N, Bauman A. Engagement and retention of participants in a physical activity website. Prev Med 2005;40:54-9 